\title{
An Experimental Study of Indoor Air Quality Enhancement Using Breathing Walls
}

\author{
Dalia Elgheznawy,", Osama Abou El Enein ${ }^{1}$, Ghada Shalaby ${ }^{1,2}$, Amany Seif $^{3}$ \\ ${ }^{1}$ Department of Architecture and Urban Planning, Faculty of Engineering, Port-Said University, Port Said, Egypt \\ ${ }^{2}$ CHP Company, Egypt \\ ${ }^{3}$ Department of Mechanical Power Engineering, Faculty of Engineering, Port Said University, Port Said, Egypt
}

Received November 7, 2021; Revised December 6, 2021; Accepted January 12, 2022

\section{Cite This Paper in the following Citation Styles}

(a): [1] Dalia Elgheznawy, Osama Abou El Enein, Ghada Shalaby, Amany Seif , "An Experimental Study of Indoor Air Quality Enhancement Using Breathing Walls," Civil Engineering and Architecture, Vol. 10, No. 1, pp. 194 - 209, 2022. DOI: 10.13189/cea.2022.100117.

(b): Dalia Elgheznawy, Osama Abou El Enein, Ghada Shalaby, Amany Seif (2022). An Experimental Study of Indoor Air Quality Enhancement Using Breathing Walls. Civil Engineering and Architecture, 10(1), 194 - 209. DOI: 10.13189/cea.2022.100117.

Copyright $@ 2022$ by authors, all rights reserved. Authors agree that this article remains permanently open access under the terms of the Creative Commons Attribution License 4.0 International License

\begin{abstract}
Recently, many studies have focused on studying indoor air quality, especially with the outbreak of COVID-19, which is one of the reasons for the increased need to improve indoor air quality. Many ideas and applications are available to incorporate nature into buildings to improve indoor air quality (IAQ) and thus secure a higher percentage of natural ventilation and pollution reduction. One of these ideas is to use "breathing walls" (BWs), which are envelope components based on porous materials. They decrease energy consumed for heating, ventilation, and air-conditioning of buildings. The study discusses the effect of using the BW approach on thermal comfort in buildings. Moreover, the improvement in the IAQ when using two models - one using BWs (applying natural and industrial materials together on the BWs, which are composed of wooden concrete hollow bricks (WCHBs)), and the other model built with solid traditional bricks (STB) - was studied through an experiment to compare air temperature, carbon dioxide $\left(\mathrm{CO}_{2}\right)$ concentration, indoor relative humidity and thermal behavior. The experiments were conducted on the two models for five months in the summer of 2019, and the results of both models were compared. From the results, it may be concluded that the model with BWs exhibits improved thermal behavior than the model with traditional bricks by recording on average three to five degrees lower than the outside temperature. Moreover, the relative humidity is lower in the WCHB model than in the STB model by $\sim 41.66 \%$ in the same conditions; however, the
\end{abstract}

$\mathrm{CO}_{2}$ concentration (ppm) in the WCHB model was lower than that in the STB model by $\sim 28.5 \%$ in the same conditions.

Keywords Breathing Walls, Health Buildings, Natural Ventilation, Indoor Air Quality, COVID-19

\section{Introduction}

During the spread of the COVID-19 virus pandemic, many countries of the world have taken many measures to reduce the repercussions of the pandemic [1]. The first preventive measure was home isolation [2]. Despite the importance of home isolation as an effective means to limit the spread of the virus, it had negative effects in unventilated spaces, which leads to health problems for individuals, such as irritability, breathing problems, and heart disease. Hence it is needed to improve air quality in indoor spaces [3, 4].

An important issue of housing quality is reported to be strongly related to building envelopes, which are the most durable building components that serve during the entire building lifetime. Moreover, envelopes have been confirmed to be the most problematic ones. Note that $\sim 80 \%$ of building failures are related to them [5]. A wall should not just be an enclosure but should provide far more than just protection. A correctly built and laid out wall is an 
important part of the house and has a long-term effect on occupant safety. A proper wall should be designed to provide multiple benefits such as it conducts self-regulation of moisture all year round, heat storage in winter, and cooling in summer and provides an appropriate environment that reduces energy consumption [6]. A common limitation is how to attain the thermal comfort of buildings by providing innovative solutions with low energy consumption. A smart building accommodates the most effective approaches of meeting its occupants' demands and adapting to the internal and external conditions [7]. Therefore, a type of smart and safe wall, breathing walls (BW), will be discussed and pivoted on the use of pores in the wall itself to reduce temperature humidity, and thus increase the quality of indoor air using natural or industrial materials or both [6].

Indoor air quality (IAQ) is important for the quality of life of individuals because they spend $\sim 90 \%$ of their time indoors [8]. IAQ primarily relates to ambient air in mechanically and naturally ventilated buildings [9]. Indoor air pollution has an important effect on people's comfort, health, and performance [10]. The IAQ effect from the infiltration of outdoor air to the indoor environment depends on the type and operation of the ventilation system of a building, which could be natural, mechanical, or hybrid [11]. Typically, IAQ is affected by three primary groups of pollutants; the first group is those primarily generated in households, namely, occupant-related pollutants such as carbon dioxide $\left(\mathrm{CO}_{2}\right)$, bio-effluents, and particulate matter (PM) in different size ranges such as personal activities (smoking, cooking, body odor, and cosmetic odors), which will be discussed here later; the second group is outdoor air pollutants such as carbon monoxide (CO); and the third group is building-related pollutants such as typically volatile organic compounds (VOCs) [12].

Indoor environmental quality (IEQ) is heavily affected by selecting materials and construction practices [13]. Although there are many individual studies on the effect of building materials on thermal comfort, daylight, and other IEQ variables, additional investigations are required to research their effects on IAQ in hot, arid climates, such as those found in Egypt [14]. Sometimes, building materials contribute to air pollution in indoor environments; thus, occupants are concurrently exposed to several contaminants as an obvious connection between building materials of different types and room temperature. The limited information for the IAQ requirements in Egypt is published on specific standards and guidelines for residential buildings in Egypt [15]. Modern construction is based on using contemporary materials such as concrete, steel reinforcement, and clay bricks. The materials used in traditional construction are available, and their installation methods are familiar to construction workers. Based on the data provided in the 2012 World Health Organization report, studies demonstrated that the highest death rates are associated with acute respiratory infections in children and heart disease caused by indoor air pollution [16].

The presence of people in a room increases $\mathrm{CO}_{2}$ concentration from an average outdoor air value of $\sim 0.04 \%$ to a value that depends on population density, outdoor airflow rate, and ventilation system efficiency. Unlike certain other pollutants (e.g., cigarette smoke), $\mathrm{CO}_{2}$ cannot be ingested, absorbed, or filtered and thus is a good measure of IAQ [17], and now generally acknowledged that concentrations $<0.1 \%$ (1000 parts per million, ppm) are required to prevent pain and headache [18].

In literature about a BW definition, Alongi et al. [19] reported that the so-called BWs are a featured type of dynamic insulation system in which penetrable air layers are bypassed by the airflow required to deliver an important change in room air. In this manner, a large proportion of the envelope is integrated into the ventilation plant as a heat recovering unit and filter. Andrea et al. [20] reported that the air porous envelope components of the BWs are dependent on permeable materials. The BWs act not only as an exchanger for ventilation heat but also as active insulation. Mazzarella et al. [21] clarified that BW elements, traversed by natural or forced airflow, rely on permeable materials because they operate as heat exchangers for recovery and active insulation, thus reducing the flow of heat conducted. They are a promising cover technology that helps reduce energy consumption in dwellings. Salmaan and Jonathan [22] confirmed that any essential material can be used as long as it can be made with millimeter air channels such as wood, glass, or concrete. Wood planks achieved rates of heat recovery by $\sim 100 \%$; however, concrete and glass samples approached values closer to $60 \%$. Swanson et al. [6] argued that the BW is an extremely significant concept for high IAQ and mold-free construction. Regrettably, certain people construe the expression literally because if we are saying these walls have lungs. The terms "breathable" and "breathability" refer to the permeable fabric designed to pass water as vapor but not liquid. Elghawaby [23, 24] reported that the term "BW" was first used in 1969 in Germany and refers to the intention to use the structure of the building to improve the air quality that reaches users within the building using natural or industrial materials or both. Breathing walls promise a conceptual design convenient to hot climates and are able to control airflow through the whole surface and cooling internal spaces in different cooling ways. Breathing walls are a biological approach in construction inspired by the concept of breathing in organisms (inhalation and exhalation), which aim to enhance the thermal behavior of traditional facades while creating a dynamic thermal atmosphere within architectural spaces. Fathy used the same expression to describe the ability to allow air to pass through walls composed of natural materials, in addition to its ability to absorb the moisture from the air, thereby reducing the air temperature by evaporative cooling. Imbabi [25] argued that the resulting breathing buildings are easy to execute, and sustainable. To the observer, the BW cladding panel 
may be indistinguishable in shape from any traditional building cladding. May [26] demonstrated that breathability in buildings is not only actually about air but also about water transmission: water as gas and water as a liquid, water in the building, water outside the building, and water in the walls, floors, and roofs themselves (though not about water in pipes). Three primary concepts have to be appreciated and used if the effect of water on buildings is to be completely known. These are vapor permeability and diffusion, which refers to the ability of a material to allow water vapor to pass through it; hygroscopicity (absorption/adsorption), which refers to the absorption/adsorption of water as vapor (as relative humidity change); and capillarity (absorption/adsorption), which refers to the absorption/adsorption of water as a liquid.

There are three levels of ventilation partitions in BWs. The outer layer is an external rain screen that should be weatherproof, and wind buffering and can be achieved using an external rain screen (made from the same material) and an isolated layer for external water. In the middle is a permeable layer of any base material that can be used as long as it can be created using millimeter-scale air channels [22]. The inner layer is a "fluid panel"; a suitable coating should be applied to the inner wall because certain coatings such as epoxy or rubber paint will close the pores inside the wall and thus prevent the three modes of transmission of moisture (water vapor permeability and diffusion, hygroscopicity, and capillarity) [6].

For breathable finishing treatments, thick-wall materials are excellent substrates for natural stucco and plaster finishes, thus providing a porous surface that readily accepts the scratch coat of both materials. This reduces labor costs because the building process is simplified, and several traditional construction steps are eliminated. Clay or lime plaster on the inside and a natural stucco, such as lime or magnesium phosphate, on the outside, are the ideal finishes, thus providing a fully breathable wall from inside to out. Covering external stucco with natural mineral silicate paints provides a breathable, durable, penetrating waterproof topcoat. As for clay, it adsorbs up to $50 \%$ its weight in excess moisture vapor from indoor air, thus further adding to a thick-wall's capacity to naturally regulate indoor air humidity. These materials, when properly applied, last for decades with little maintenance; moreover, they can be tinted in various colors. An indoor plaster finish can be just as smooth as wallboard, thus providing a professional look to the interior decor. Moreover, plaster can blend well with an intersecting gyp-board-covered interior partition wall [6].

In this study, the concept of BWs will be examined in Port Said, Egypt. Port Said is a high-humidity coastal city. A comparative study of the BWs and traditional solid walls is performed, including the assessment of the thermal performance of the walls and their effectiveness in reducing moisture and levels of $\mathrm{CO}_{2}$ gas. The $\mathrm{BW}$ bricks are formed using sustainable materials, i.e., a mixture of cement, sand, and sawdust; however, the solid red bricks are used as traditional walls.

\section{Materials and Methods}

To assess and compare the performance of the BWs against traditional walls, an experiment was performed during the summer of 2019 on the roof of the main building of the Faculty of Engineering, Port Said University, Port Said City, Egypt. Two models were constructed and compared with each other. The first model was constructed with solid traditional bricks (STBs); however, the second was constructed with the proposed BWs composed of wooden concrete hollow bricks (WCHBs). Both models were made with the same inner space dimensions $100 \mathrm{~cm}$ width $\times 100 \mathrm{~cm}$ length $\times 100 \mathrm{~cm}$ height and placed at the same orientation. The STB and WCHB models were spaced $100 \mathrm{~cm}$ apart. Figure 1 shows the layout of the experimental setup. Both models are placed at a distance so that neither of them casts a shadow on the other.

\subsection{Case Study Climate Data}

Port Said's climate is classed as BWh by Köppen climate classification. However, summers are hot and humid due to Mediterranean Sea winds. The average relative humidity in Port Said is 68 percent, with temperatures ranging from $11.1^{\circ} \mathrm{C}$ to $17.4^{\circ} \mathrm{C}$ in January (the coldest winter month) and $24.2^{\circ} \mathrm{C}$ to $30.3^{\circ} \mathrm{C}$ in August (the warmest summer month) (Weather-atlas, 2020). 


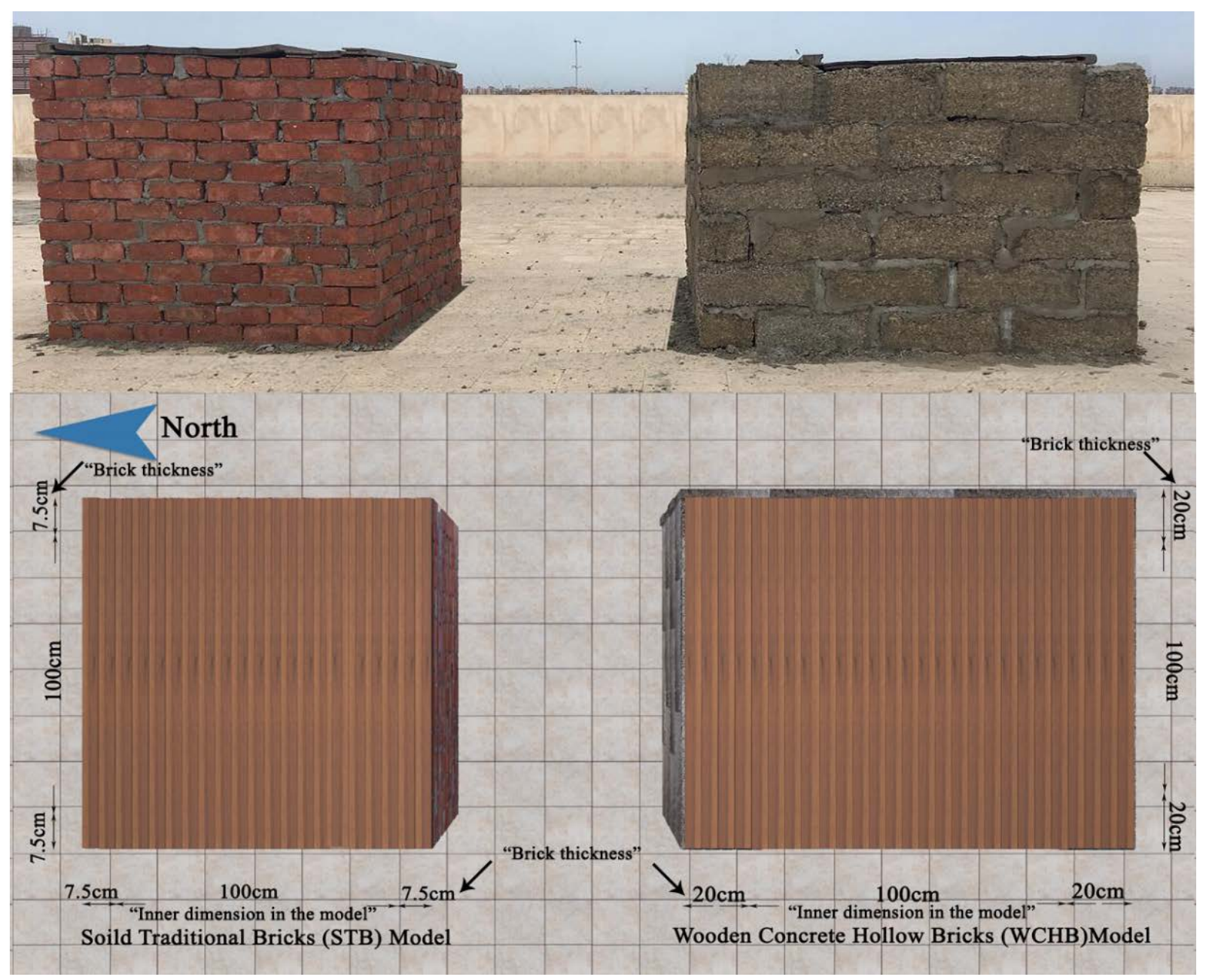

Figure 1. The STB and the WCHB models

\subsection{The STB Model}

Figure 2(a) shows the STB model is constructed with STBs.

Typically, as shown in Figure 2(a), the formed STB block STB model measures $7.5 \mathrm{~cm} \times 7.5 \mathrm{~cm} \times 22.5 \mathrm{~cm}$.

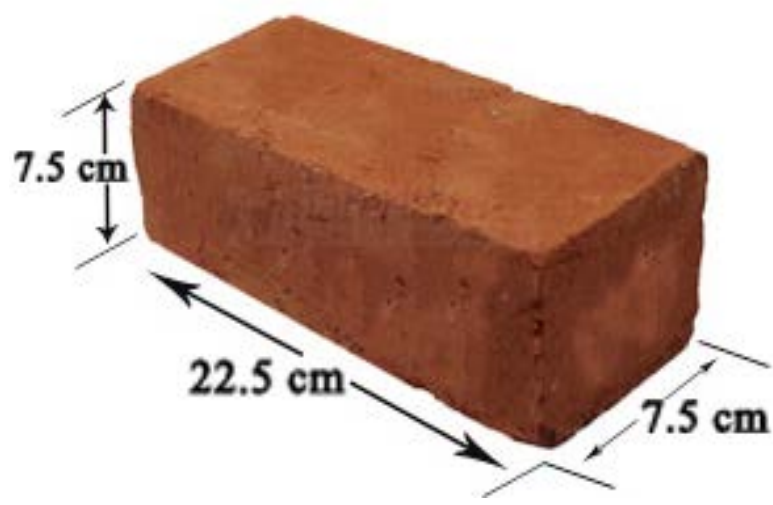

(A)

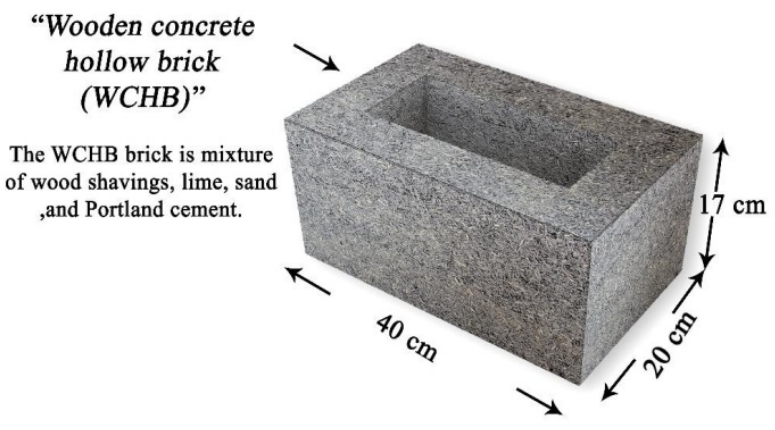

(B)

Figure 2. Part (A) Solid brick dimensions, Part (B) WCHB brick dimensions. 


\subsection{The WCHB Model}

The wood-concrete mixture of wood shavings, lime, and Portland cement is used to compose the WCHB block forms. The higher the proportion of wood, the lower the density of the wall and it improves in its performance of thermal insulation [27]. The relative proportions in the brick form mix used in this study are particularly $85 \%$ wood and $15 \%$ cement by volume and $62 \%$ cement with $38 \%$ wood by weight [6]. Typically, as shown in Figure 2(b), the formed WCHB block has a size of $40 \mathrm{~cm} \times 20 \mathrm{~cm}$ $\times 17 \mathrm{~cm}$ with dimensions of $10 \mathrm{~cm} \times 30 \mathrm{~cm}$.

\subsection{Measurements and Experimentation Procedure}

The experiments were conducted at the Faculty of Engineering, Port Said University, Egypt, from June to October 2019. Table 1 lists the different experiments and the operating conditions for each experiment. Figure 3 shows the devices that measure each experiment.

Solar radiation, atmospheric temperature, and wind velocity were measured for each experiment. All measurements were recorded to evaluate the performance of the STB and WCHB models under the local climatic conditions. To examine the thermal performance of these two models, the inner space air temperatures in each model were measured. Considering the water transmission, water may transfer through the building by three mechanisms, i.e., vapor diffusion, hygroscopicity, and capillarity. The relative humidity of air has a significant impact on thermal comfort $[28,29]$. To examine the water transmission through STB and WCHB models, additional experiments were performed to measure the relative humidity and the humidity ratio in the inner space air of these two models. Typically, IAQ is affected by generating household pollutants such as $\mathrm{CO}_{2}$, bio-effluents, and PM through personal habits such as smoking, use of perfumes, and cooking. To evaluate the ability of the STB and WCHB models to divest themselves of the internal generating pollutant, the $\mathrm{CO}_{2}$ concentration was measured in the two models under the same weather conditions.

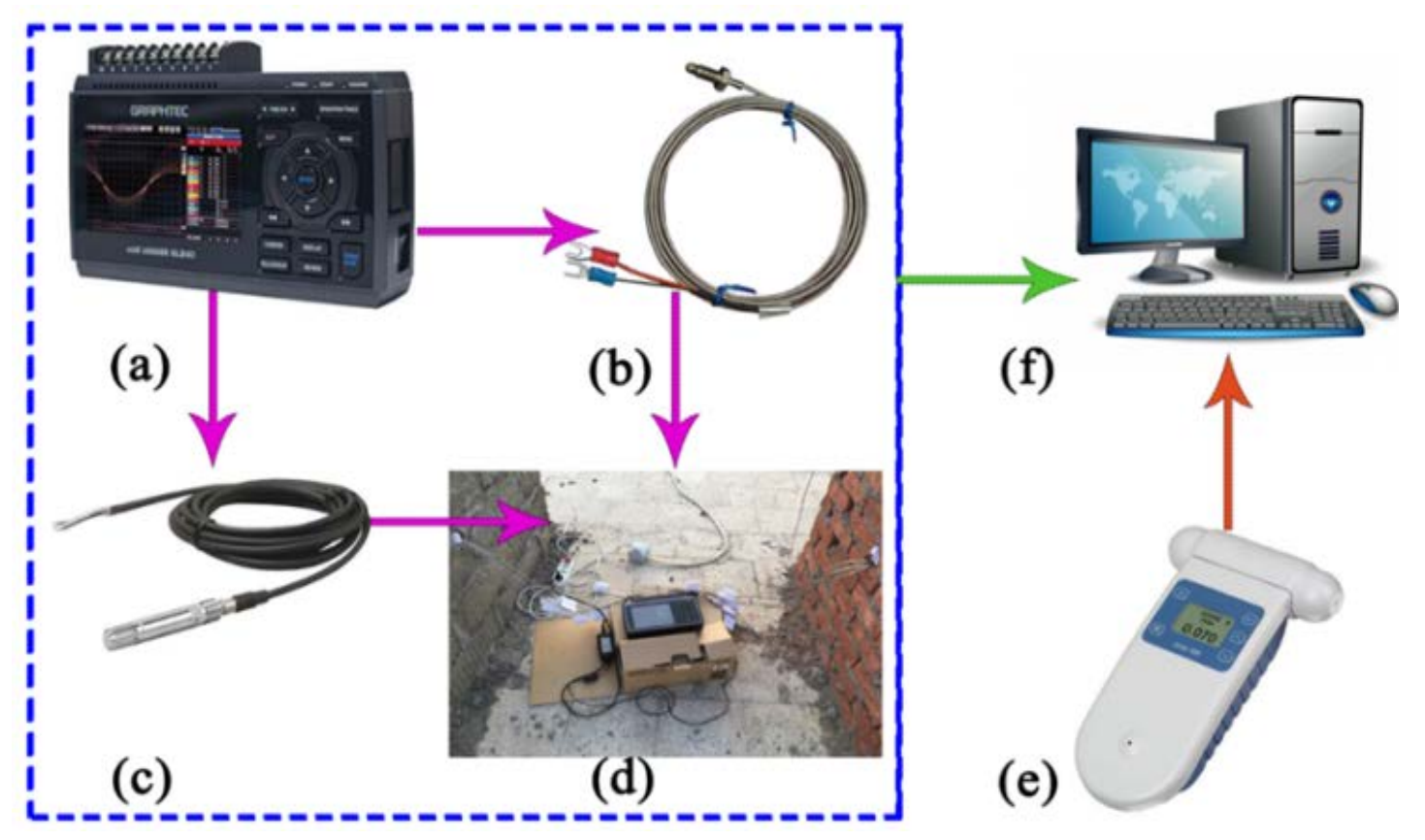

Figure 3. (a) data logger (Graphtec midi data logger GL-820) device, (b) calibrated thermocouples (K-type), (c) humidity probe tool, (d) Method of connecting the device "Graphtec midi data logger GL-820" with the two models to measure the temperature and humidity inside them, (e) "Aeroqual S500" device to measure $\mathrm{CO}_{2}$ concentration inside the two models, (f) connecting with PC for collecting data.

Table 1. The experiments performed and the operating conditions.

\begin{tabular}{|c|c|c|c|c|}
\hline Experiment & Date & Outdoor temperature $\left({ }^{\circ} \mathbf{C}\right)$ & Relative humidity (\%) & Wind speed (km/h) \\
\hline $\begin{array}{c}\text { Temperature measurement } \\
\text { (June) }\end{array}$ & $6 / 15 / 2019$ & $30: 23$ & 72 & 13 \\
\hline $\begin{array}{c}\text { Temperature measurement } \\
\text { (July) }\end{array}$ & $7 / 15 / 2019$ & $32: 26$ & 70 & 16 \\
\hline $\begin{array}{c}\text { Temperature measurement } \\
\text { (August) }\end{array}$ & $8 / 15 / 2019$ & $31: 26$ & 64 & 19 \\
\hline Relative humidity & $9 / 15 / 2019$ & $29: 24$ & 62 & 16 \\
\hline $\begin{array}{c}\text { Carbon dioxide }\left(\mathrm{CO}_{2}\right) \\
\text { concentration }\end{array}$ & $10 / 15 / 2019$ & $28: 23$ & 73 & 19 \\
\hline
\end{tabular}


Eighteen calibrated thermocouples (K-type) were connected on two wooden grids (nine for each grid) placed in STB and WCHB models to measure inner space air temperatures. An additional thermocouple was used to measure the outdoor temperature. The temperature sensors were connected to a thermocouple data logger (Graphtec midi data logger GL-820) that records the temperatures every 15 min from 10:00 a.m. to 8:00 p.m. as shown in Figures 4, 5, 6, and 7(a, b). The temperatures of both models, the STB model and WCHB model, were measured over 3 months in the summer of 2019 in June, July, and August. A day was selected in the middle of each month to examine the thermal behavior of these two models for 10 consecutive hours during the day.

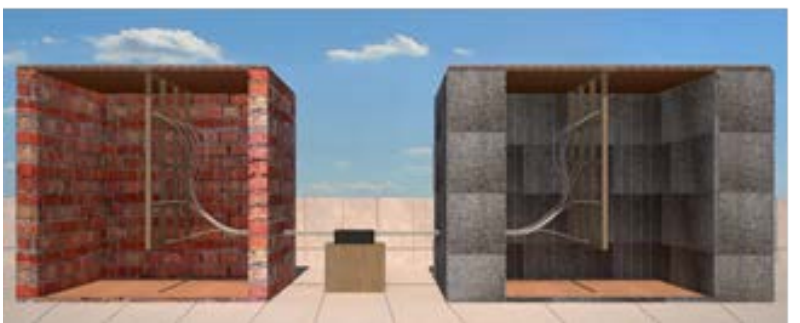

Figure 4. Eighteen calibrated thermocouples (K-type) are connected on two wooden grids (Nine for each grid) placed in the STB and WCHB models to measure inner space air temperatures. And they are connected to a thermocouple data logger (Graphtec midi data logger GL-820) that records the temperatures.

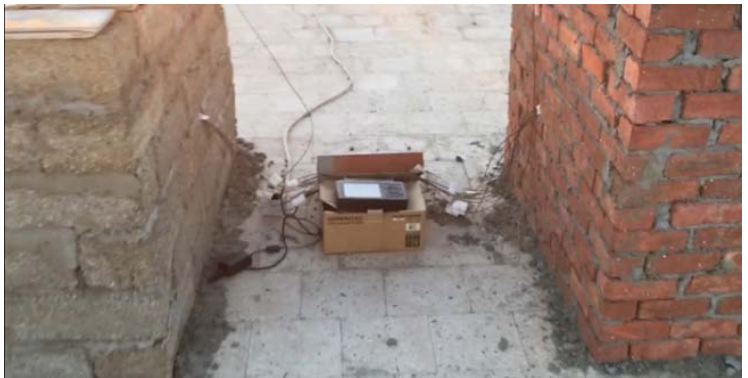

Figure 5. Method of connecting the device "Graphtec midi data logger GL-820" with the two models to measure the temperature inside them

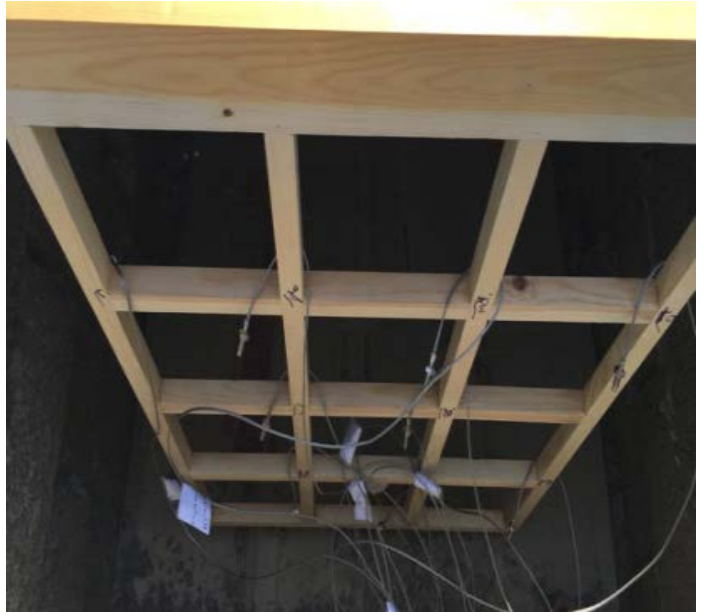

Figure 6. Thermocouples fixed on the movable wooden grid.

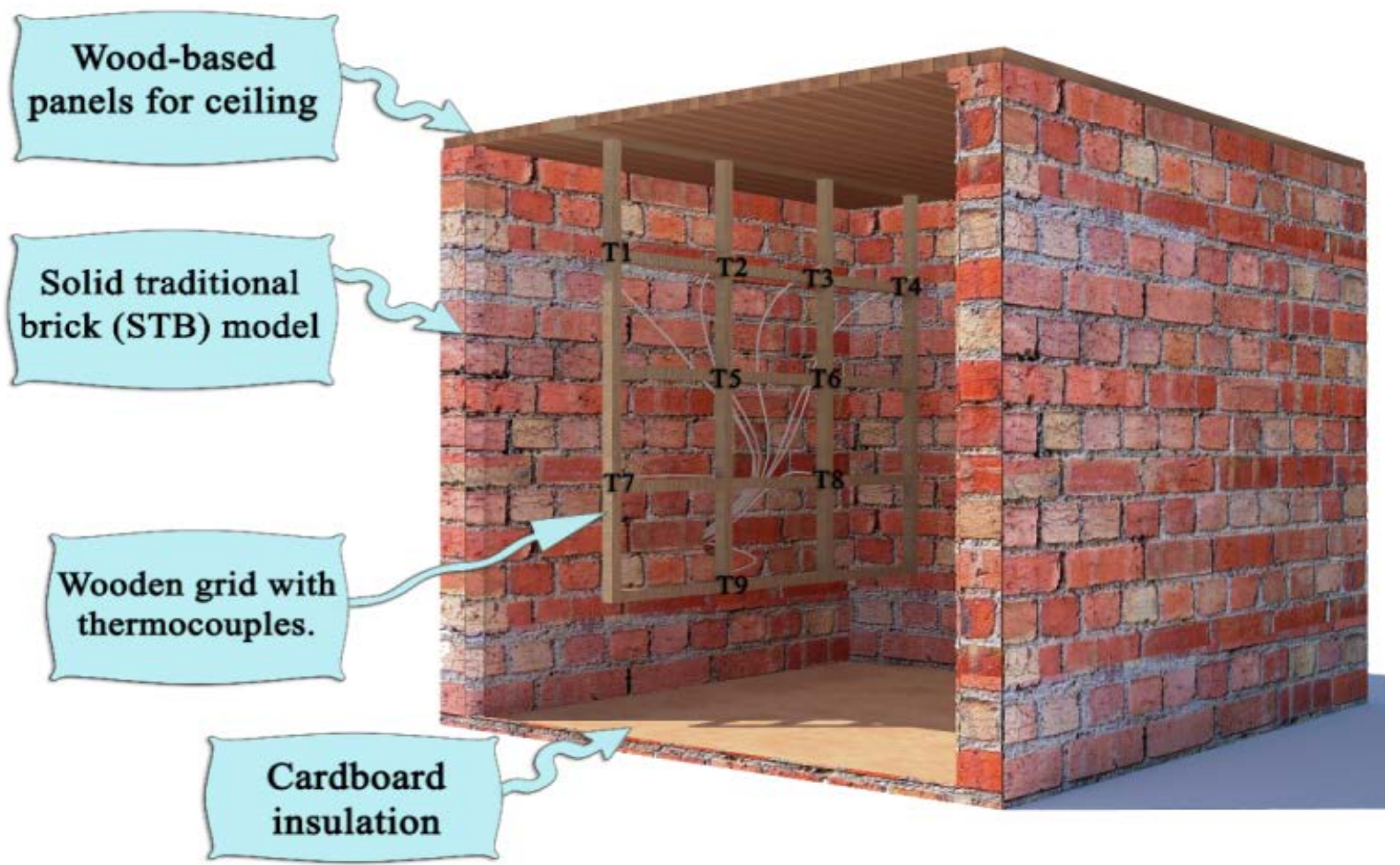

Figure 7(a). Temperature sensors positions (T1-T9) on the wooden grid inside the STB model 


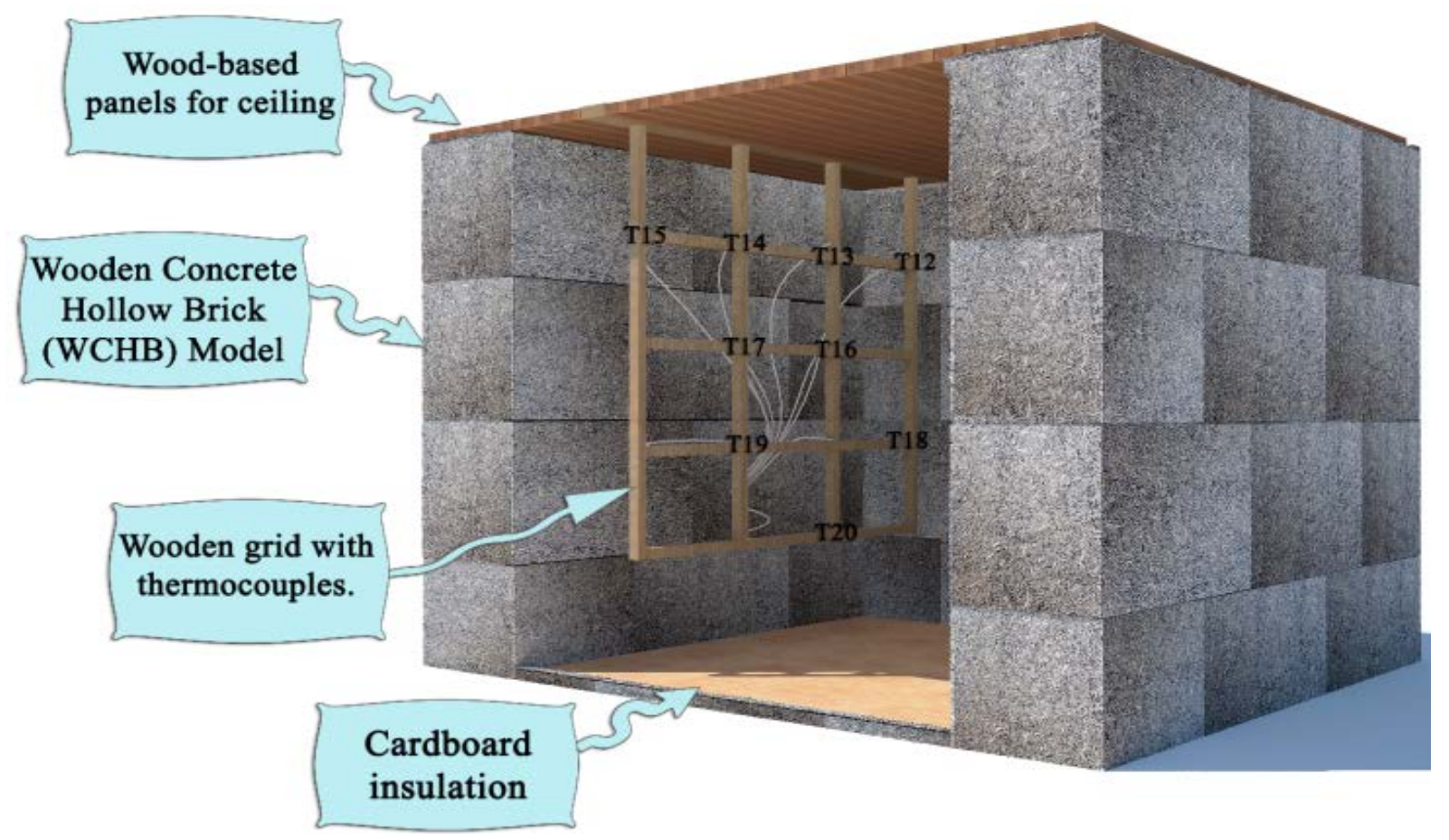

Figure 7(b). Temperature sensors (T12-T20) positions on the wooden grid inside the WCHB model

\subsection{The Measuring Instruments' Accuracy}

The measured parameters included temperatures, solar radiation, wind velocity, relative humidity, and $\mathrm{CO}_{2}$ concentration. Table 2 lists the accuracy, range, and percentage error for the different instruments. All values were small compared to the data obtained and reported to be within the allowable ranges of the measurements of the devices.

Table 2. Accuracy and error for the measuring instruments

\begin{tabular}{|c|c|c|c|c|}
\hline No & Instrument & Accuracy & Range & $\begin{array}{c}\text { \% } \\
\text { Error }\end{array}$ \\
\hline 1 & $\begin{array}{c}\text { Calibrated } \\
\text { thermocouples } \\
\text { (K-type) }\end{array}$ & $+0.1^{\circ} \mathrm{C}$ & $\begin{array}{c}-270^{\circ} \\
\mathrm{C} \text { to } \\
1820^{\circ} \mathrm{C}\end{array}$ & $0.005 \%$ \\
\hline 2 & Aeroqual S500 & $\begin{array}{c}+5 \% \text { of } \\
\text { reading }\end{array}$ & $\begin{array}{c}0-5000 \\
\mathrm{ppm}\end{array}$ & $20 \mathrm{ppm}$ \\
\hline 3 & $\begin{array}{c}\text { Graphtec midi data } \\
\text { logger } \\
\text { GL-820-Humidity } \\
\text { Measurement "probe } \\
\text { tool" }\end{array}$ & & $\begin{array}{c}0 \%- \\
100 \%\end{array}$ & \\
& \multicolumn{2}{|c}{} & & \\
\hline
\end{tabular}

\subsection{Study Limitations}

The WCHB uses a different brick size compared to the STBs, but with the same thickness of each brick into the model also the same inner space dimensions.

The study records the temperatures every $15 \mathrm{~min}$ from 10:00 a.m. to 8:00 p.m. (the most effective hours of the day), the aim of the study is to study the breathing walls and their applications in hot and hot humid climate, so the days selected to examine present the average of the days of the hottest months in such climate in Egypt.
The study of $\mathrm{CO}_{2}$ concentration was done primarily to evaluate the ability of the WCHB model to strip itself of internal pollutants. To show the feasibility of studying it in the future or not, as a new subject, the concentration of $\mathrm{CO}_{2}$ was measured in the two models under the same atmospheric conditions. However, the study recommends conducting more studies in the future. The same with the humidity study.

\section{Results and Discussion}

\subsection{Thermal Distribution of the STB and WCHB Models}

The thermal performance of STB and WCHB models was assessed using the inside air temperature measurements. Three transport modes for heat can be identified as radiation, convection, and conduction [30, 31] as shown in Figures 8 (a, b). Figures 9 (a, b, c), 10 (a, b, c), and $11(\mathrm{a}, \mathrm{b}, \mathrm{c})$ show variation in the temperature distribution of certain nodes in the STB model (T2, T5, and T8) and the corresponding nodes in the WCHB model (T13, T16, and T19) on three middays of June, July, and August, respectively.

Obviously from Figure 9(a, b, c), temperature distributions vary with time with the peak occurring at 2:00 p.m. The temperatures of the STB model were greater than those of the WCHB model by $\sim 3^{\circ} \mathrm{C}-5^{\circ} \mathrm{C}$ till 5:00 p.m., and then the differences between temperature distributions in both models' decay after this time. Smaller temperature differences between different nodes of the WCHB model than those of the STB model could be seen. 


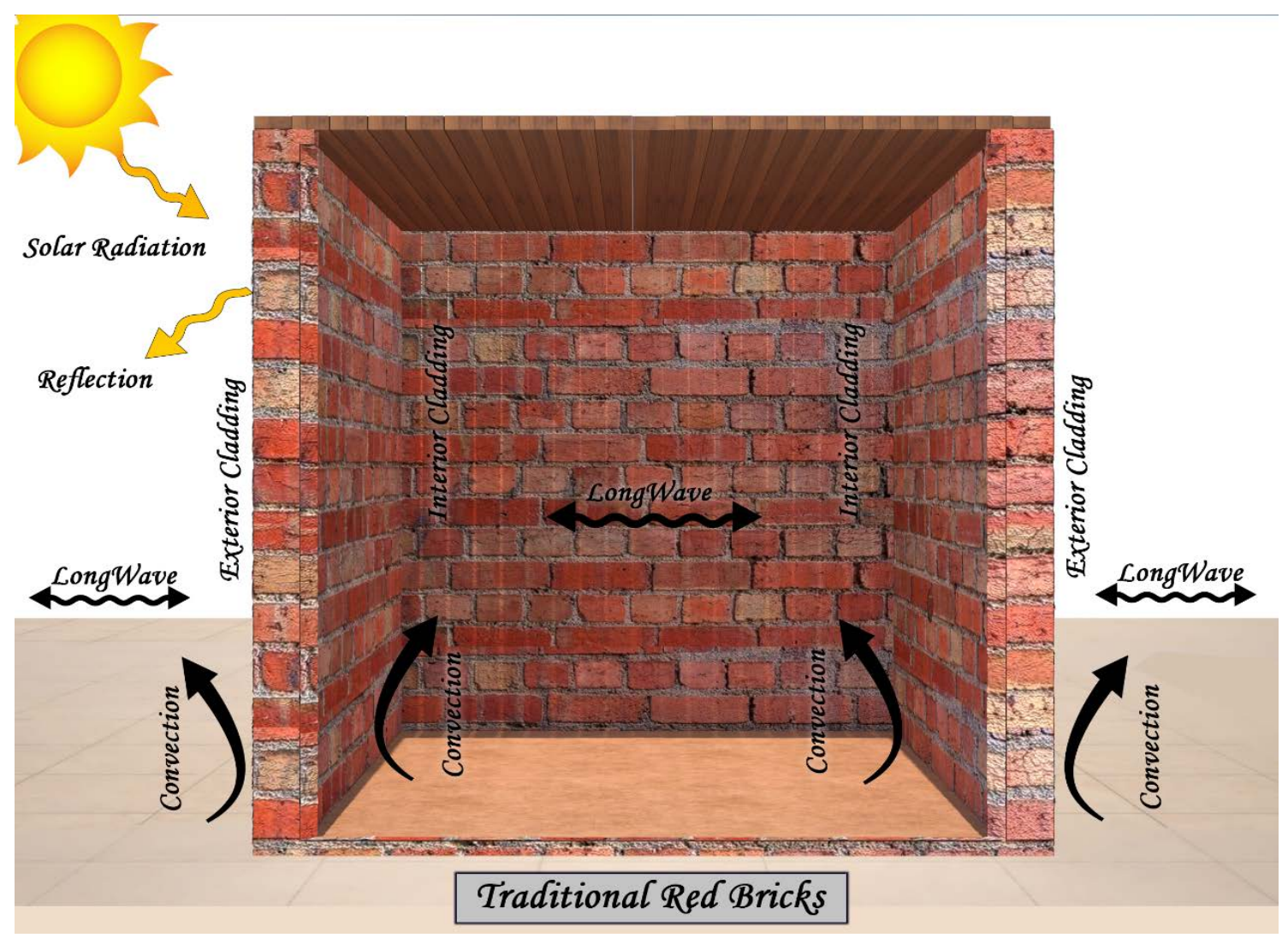

Figure 8 (a). Illustration of heat fluxes occurring in and around STB model.

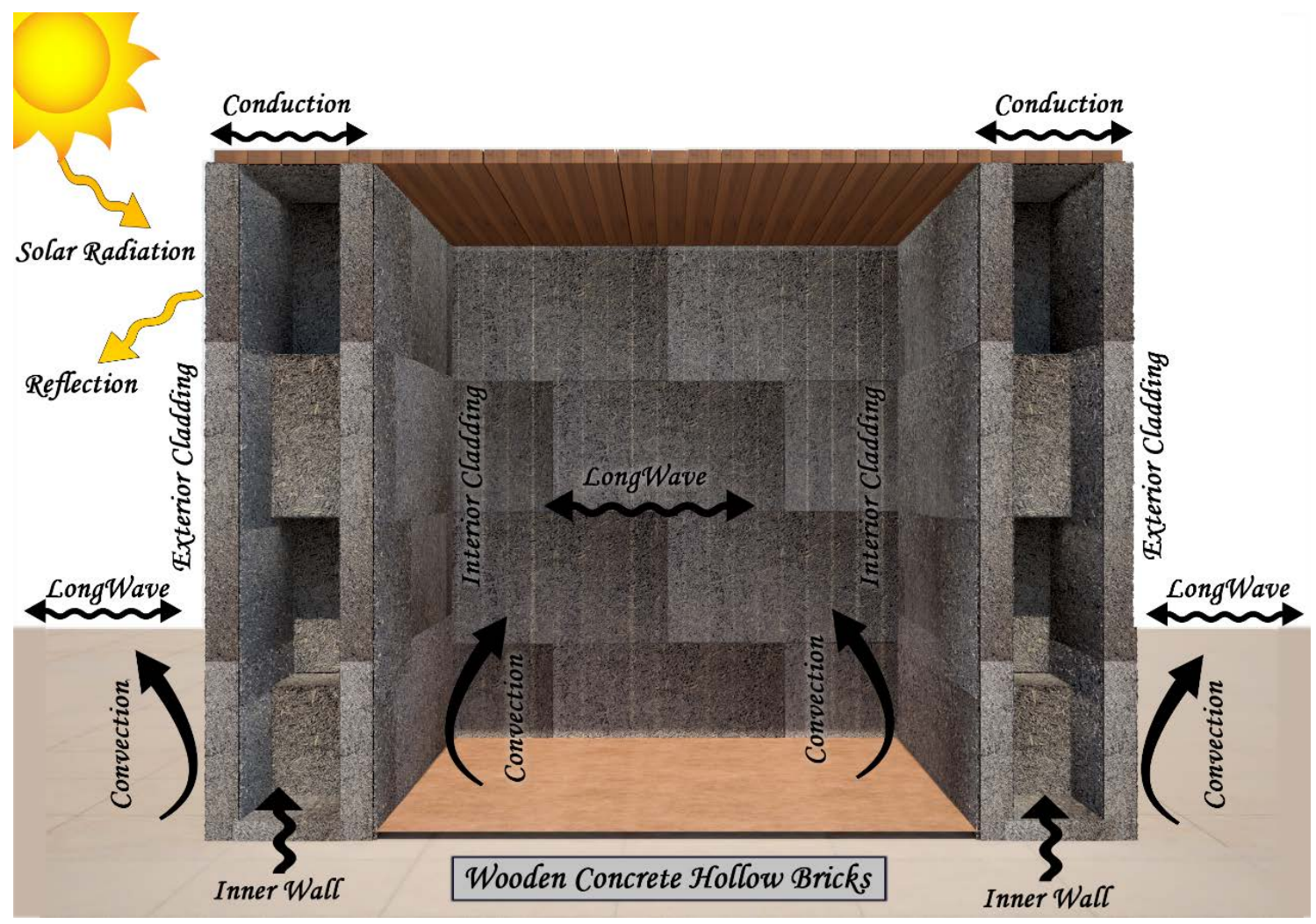

Figure 8 (b). Illustration of heat fluxes occurring in and around WCHB model. 


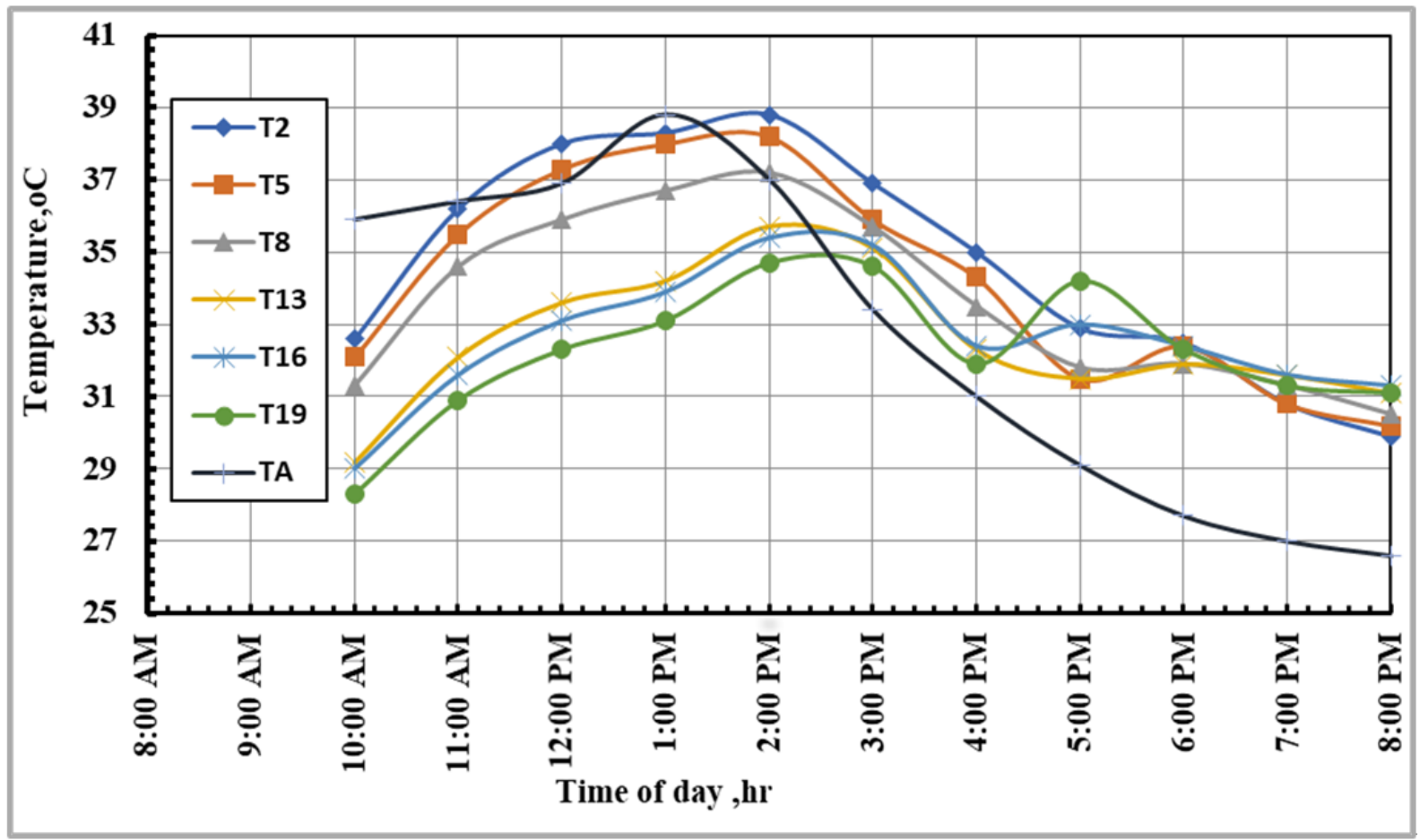

Figure 9 (a). Temperature variation with time on mid of June for the STB and WCHB models (T2, T5 and T8 for the STB model, T13, T16 and T19 for the WCHB model and TA for outdoor air temperature).

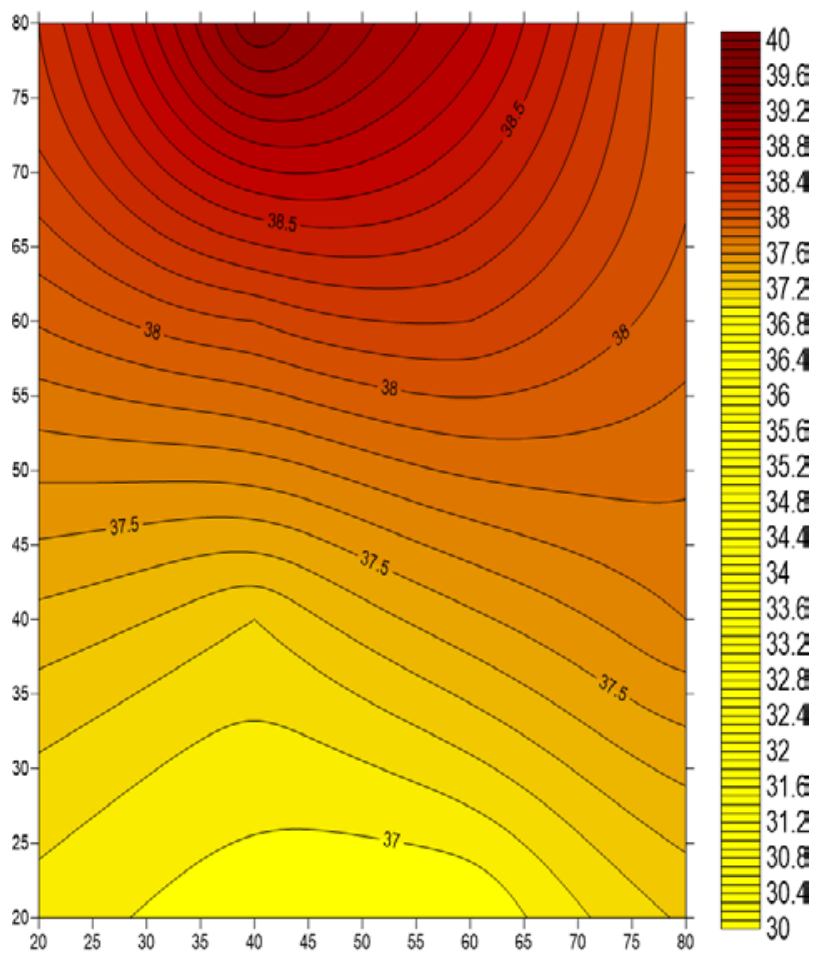

Figure 9 (b). Solid traditional bricks (STB) at 2 PM

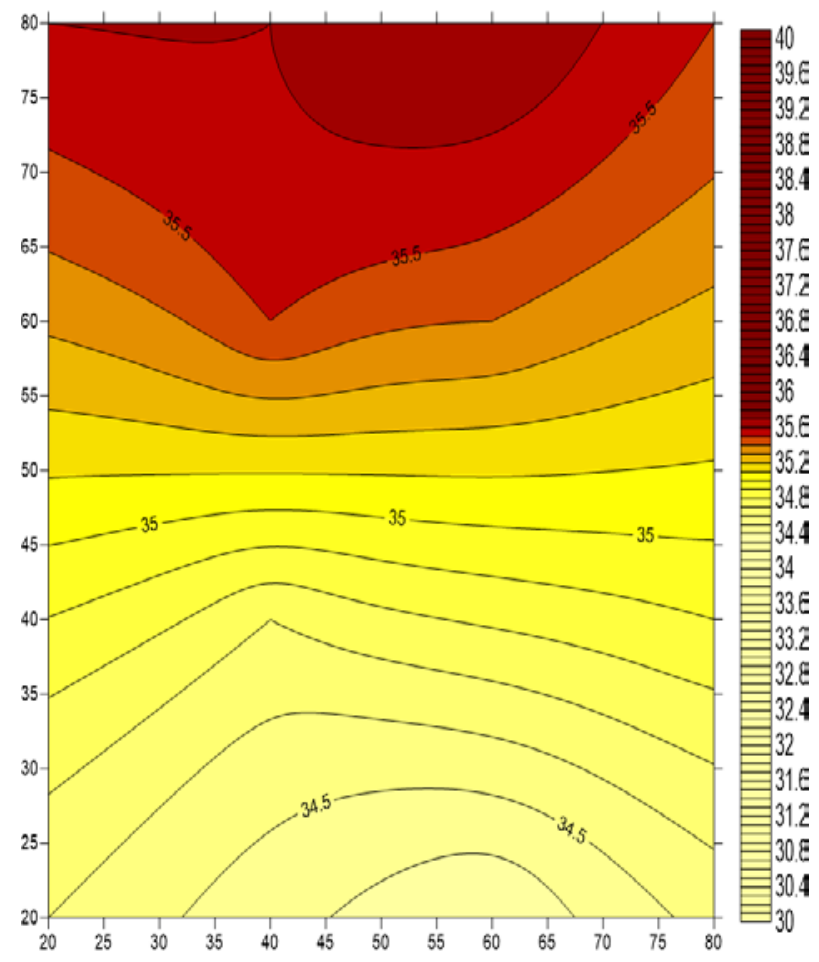

Figure 9 (c). Wooden concrete hollow bricks (WCHB) at 2 PM 


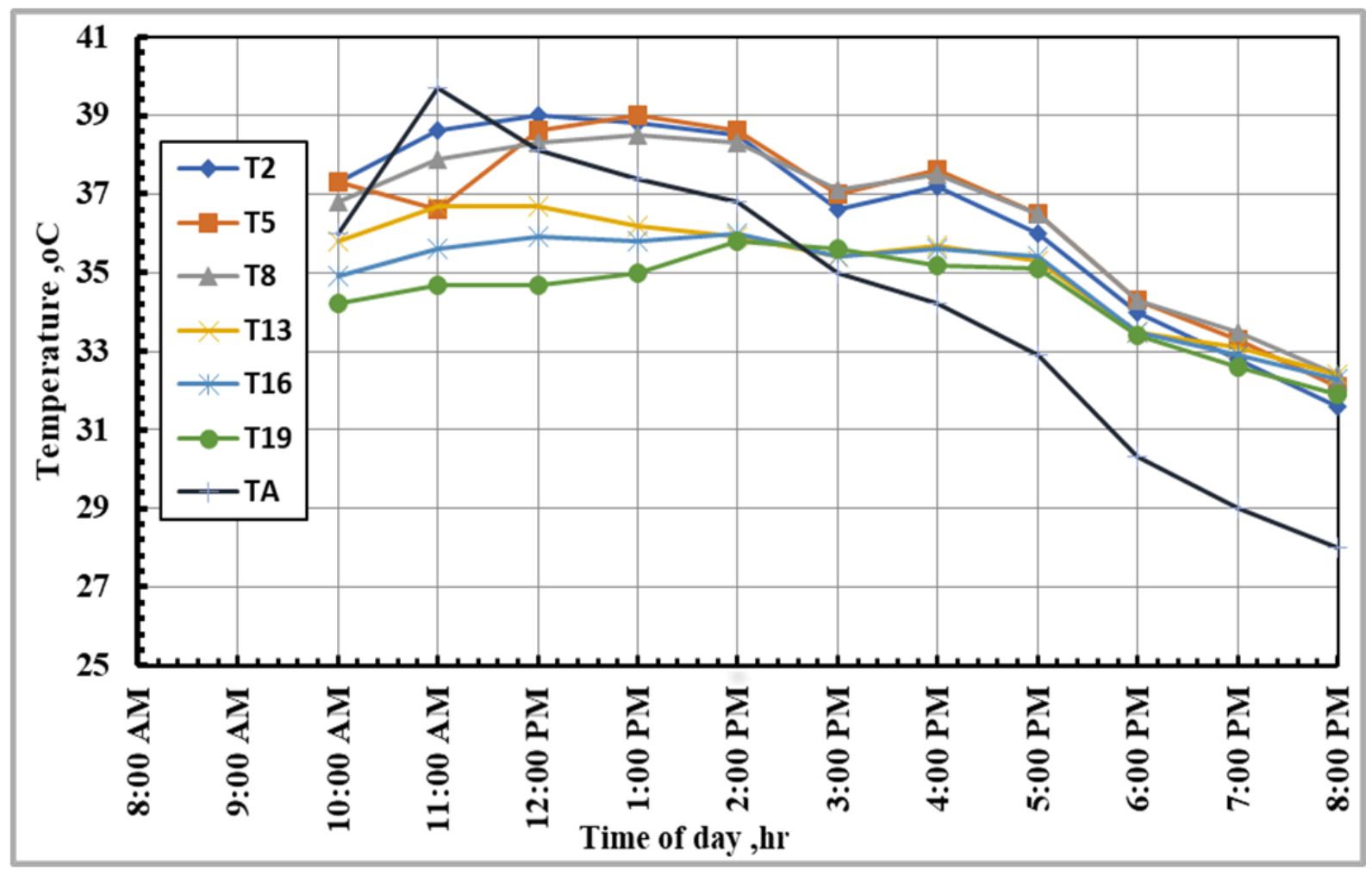

Figure 10 (a). Temperature variation with time on mid of July for the STB and WCHB models (T2, T5 and T8 for the STB model, T13, T16 and T19 for the WCHB model and TA for outdoor air temperature).

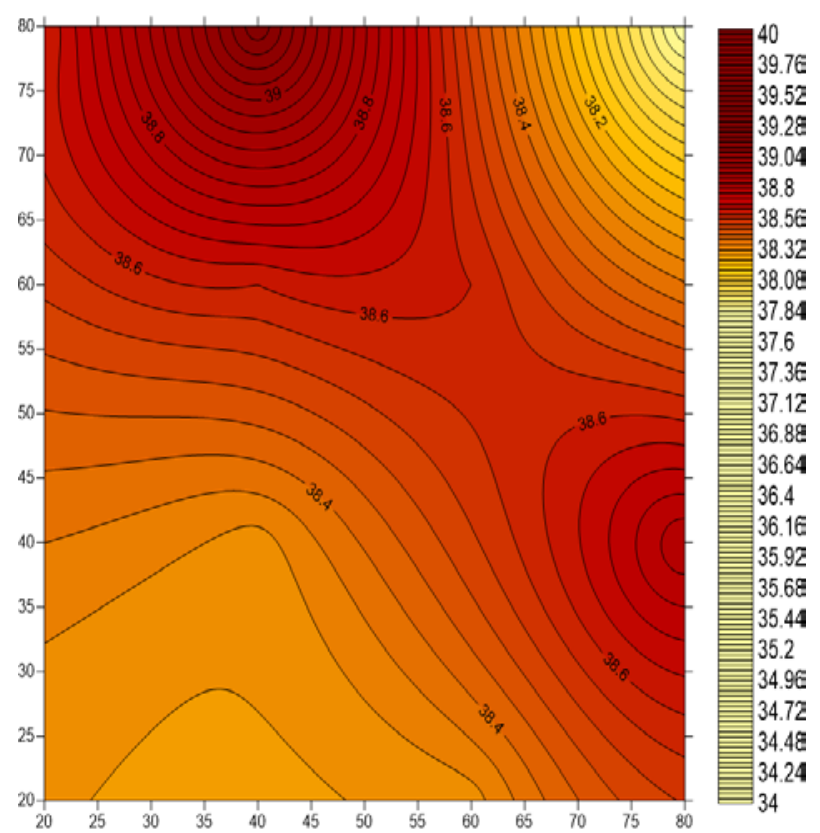

Figure 10 (b). Solid traditional bricks (STB) at 2 PM

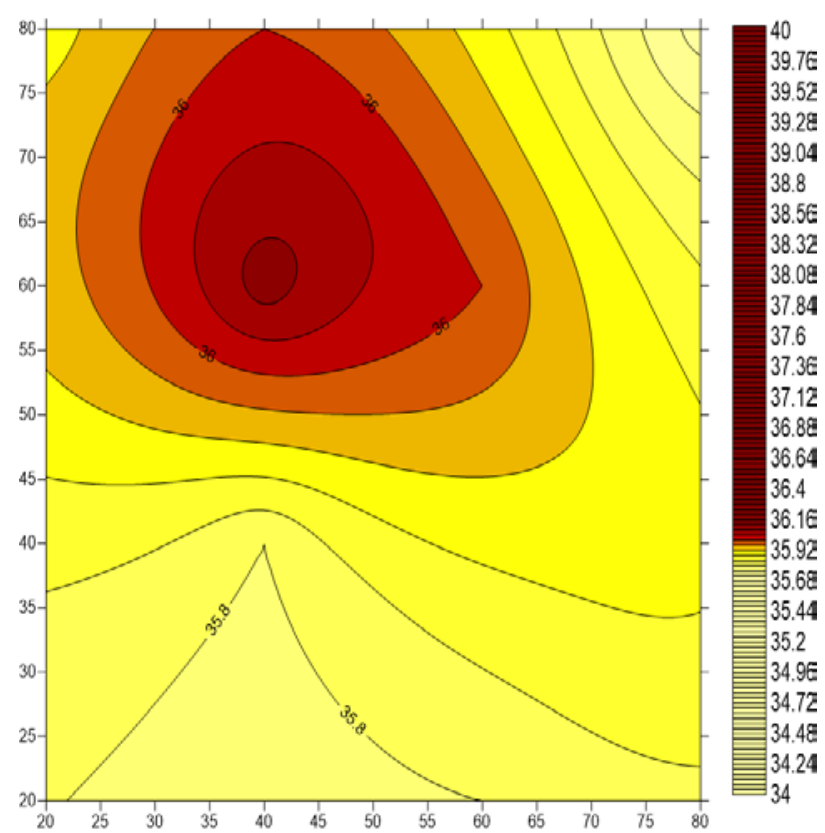

Figure 10 (c). Wooden concrete hollow bricks (WCHB) at 2 PM 


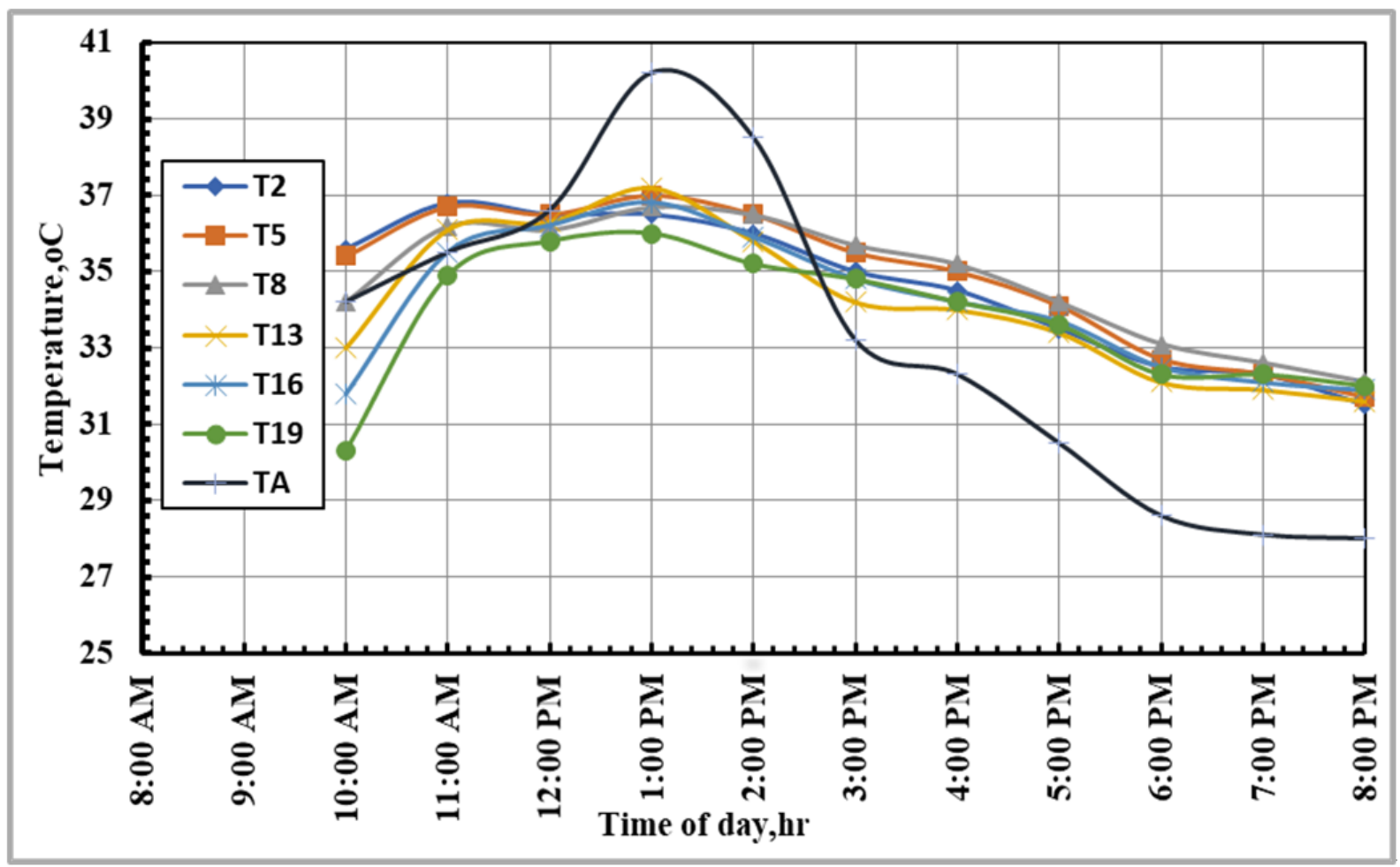

Figure 11 (a). Temperature variation with time on mid of August for the STB and WCHB models (T2, T5 and T8 for the STB model, T13, T16 and T19 for the WCHB model and TA for outdoor air temperature).

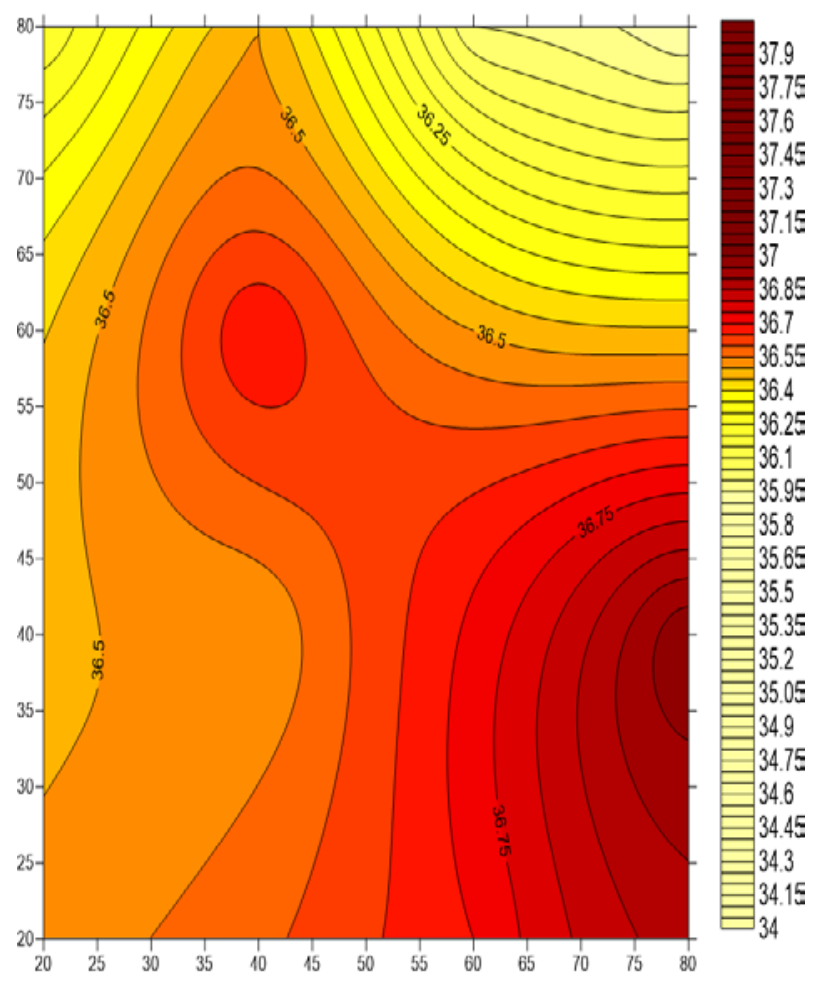

Figure 11 (b). Solid traditional bricks (STB) at 2 PM

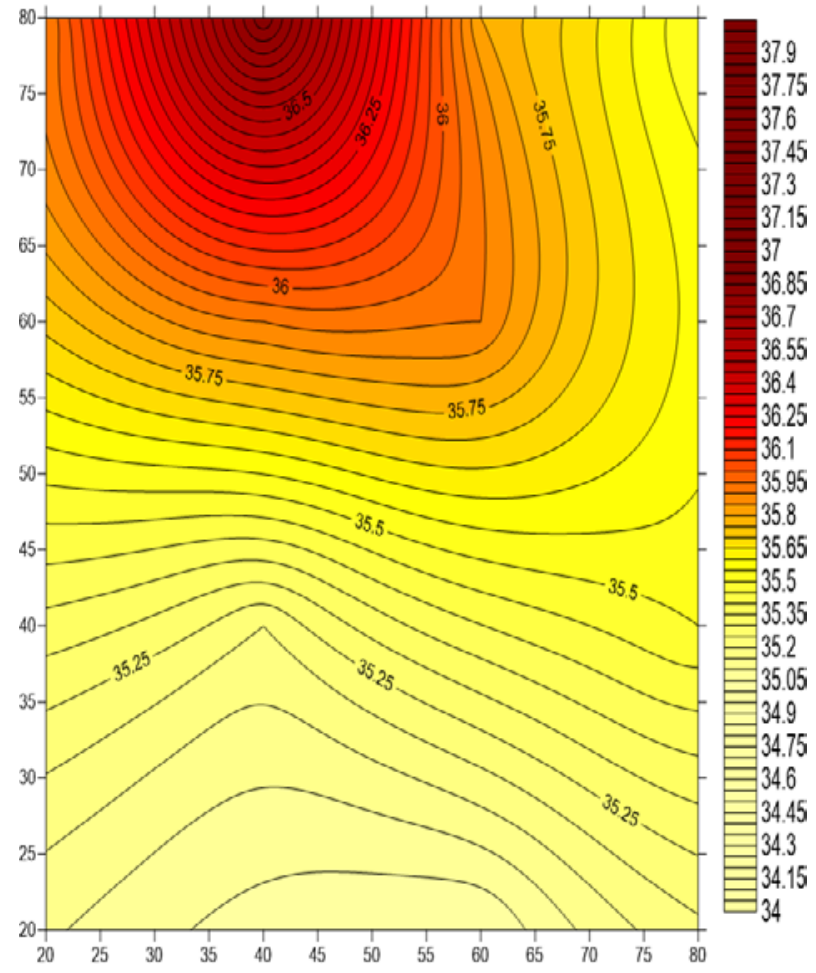

Figure.11 (c). Wooden concrete hollow bricks (WCHB) at 2 PM 


\section{2. $\mathrm{CO}_{2}$ Concentration}

As the $\mathrm{CO}_{2}$ has considerable effects on thermal comfort and IAQ, the diffusion of $\mathrm{CO}_{2}$ gas in the STB and WCHB models has been experimentally tested in both models where the $\mathrm{CO}_{2}$ is generated from a chemical reaction of 50 g sodium carbonate with $1.8 \mathrm{~L}$ diluted $0.1 \mathrm{M}$ hydrochloric acid as per the following chemical reaction:

$$
\mathrm{Na}_{2} \mathrm{CO}_{3}+2 \mathrm{HCl} \rightarrow 2 \mathrm{NaCl}+\mathrm{H}_{2} \mathrm{O}+\mathrm{CO}_{2} \text { (gas) }
$$

Two centered, wide tubes were placed in the two models, sodium carbonate was spread in the tubes, dilute $\mathrm{HCl}$ was injected into the tubes via a flexible plastic hose, the concentrations of $\mathrm{CO}_{2}$ were determined using an Aeroqual S500 device, see Figure 12. The model inner space temperature affects the diffusion of $\mathrm{CO}_{2}$ and the rate of inout air infiltration. Figure 13 shows the variation of $\mathrm{CO}_{2}$ concentration of the STB and WCHB models during the day.
As shown in Figure 13, the results of the chemical reaction of the average $\mathrm{CO}_{2}$ concentrations of the STB model are spontaneously greater than those of the WCHB model. The maximum recorded $\mathrm{CO}_{2}$ concentration in STB is $0.14 \%$; however, the corresponding concentration in the WCHB model is $0.1 \%$. Knowing that the concentration percentage wares until it reaches the ambient concentration of $0.04 \%$ through the time of the experiment of $1 \mathrm{~h}$ at both models.

This is attributed to the dilution air within the WCHB model with the infiltrated air from the loose walls of the model. However, the higher average temperature of the STB model makes the $\mathrm{CO}_{2}$ diffuse faster than that in the WCHB model. Owing to higher permeability, the WCHB walls act as the BW of the model.

From this, we report that the $\mathrm{CO}_{2}$ concentration (ppm) in the model WCHB was lower than that in the STB model in the same conditions [33].

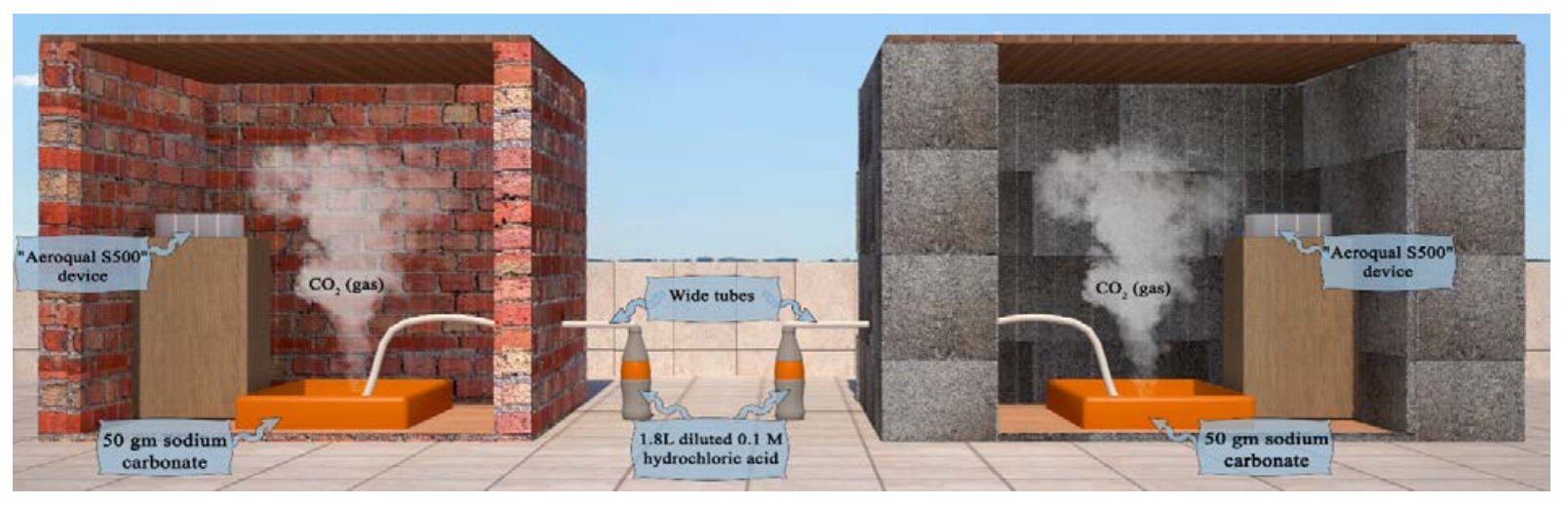

Figure 12. The $\mathrm{CO}_{2}$ experiment in the STB and WCHB models

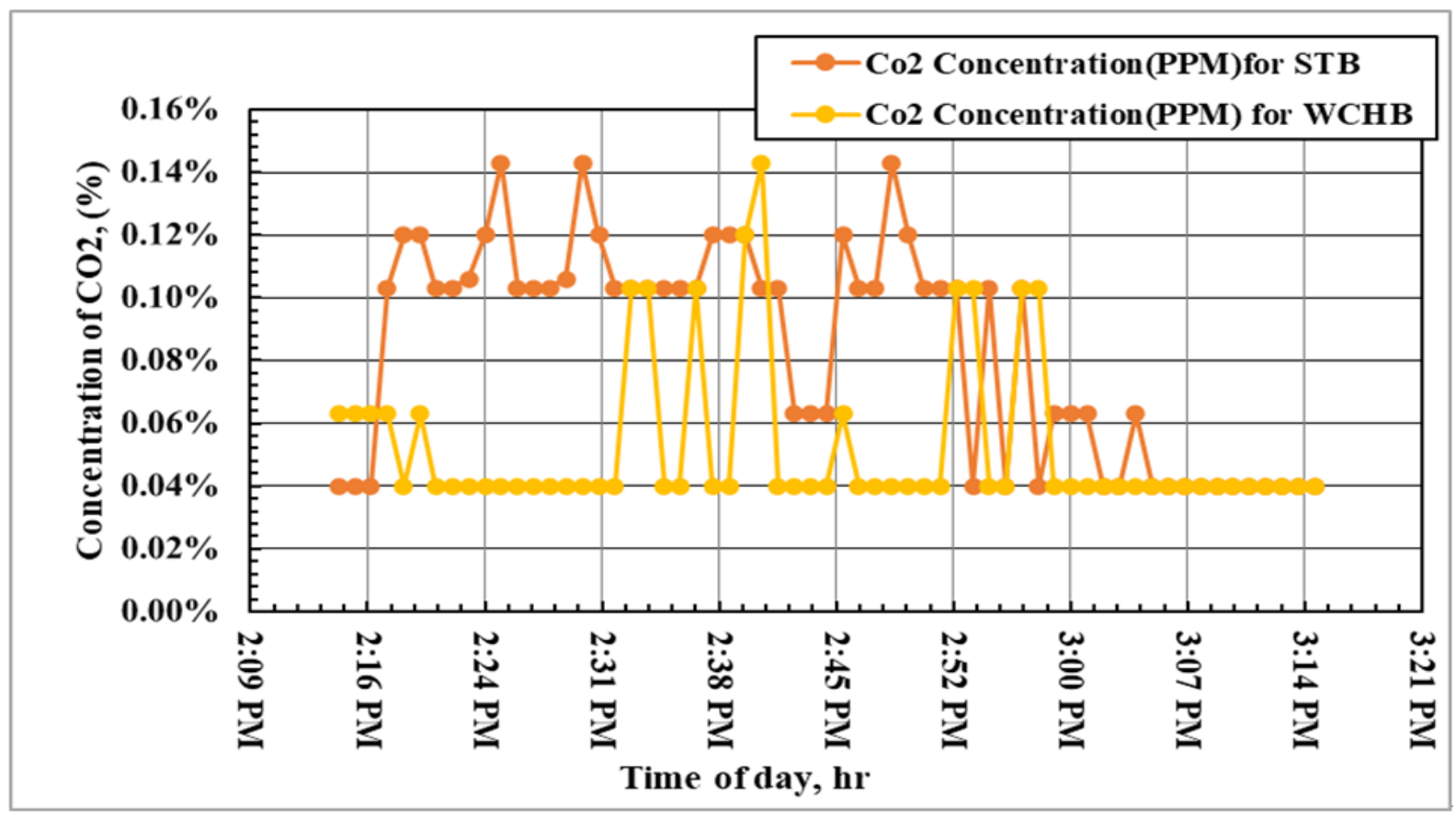

Figure 13. $\mathrm{CO}_{2}$ Concentration (PPM)\% and Time diagram in (WCHB) model and (STB) model in mid of October 


\subsection{Indoor Humidity}

It is important to provide proper humidity, in addition to temperature. The STB and WCHB models were tested to investigate their effectiveness for regulating the relative humidity in the inner space air. The two models were insulated at the bottom with cartoon sheets. To increase the relative humidity of the inner air in the models, equal amounts of water ( $4 \mathrm{~L}$ in volume) were poured into the floor of the two models, and then the models are closed. The next day, the relative humidity probe connected with the Graphtec midi data logger GL-820 was used to record the relative humidity in the STB and WCHB models over the time of the experiment, as shown in Figure 14.

Figure 15 shows the overall average relative humidity within the WCHB model is lower than that of the STB model. This accounted for the high permeability of the
WCHB model walls, the movement of air within the hollow wall in the WCHB model, and the pores caused by the sawdust help to get rid of moisture. The air inside the WCHB model almost draws near the humidity of the external air, and then the humidity of the air inside the WCHB model decreases compared to the external air, thus proving the permeability of the wall and that it is already a "BW."

The diagram in Figure 16 shows that the relative humidity is lower in the WCHB model than in the STB model compared to the air humidity, and then the relative humidity of the external air converges with the WCHB model, thus confirming the permeability of the wall and that it is already a BW. The wooden concrete acts as a vapor regulator, a vaporizer, and reduces relative humidity levels in the interior, which indicates the wall structure helps to avoid the growth of molds [2].

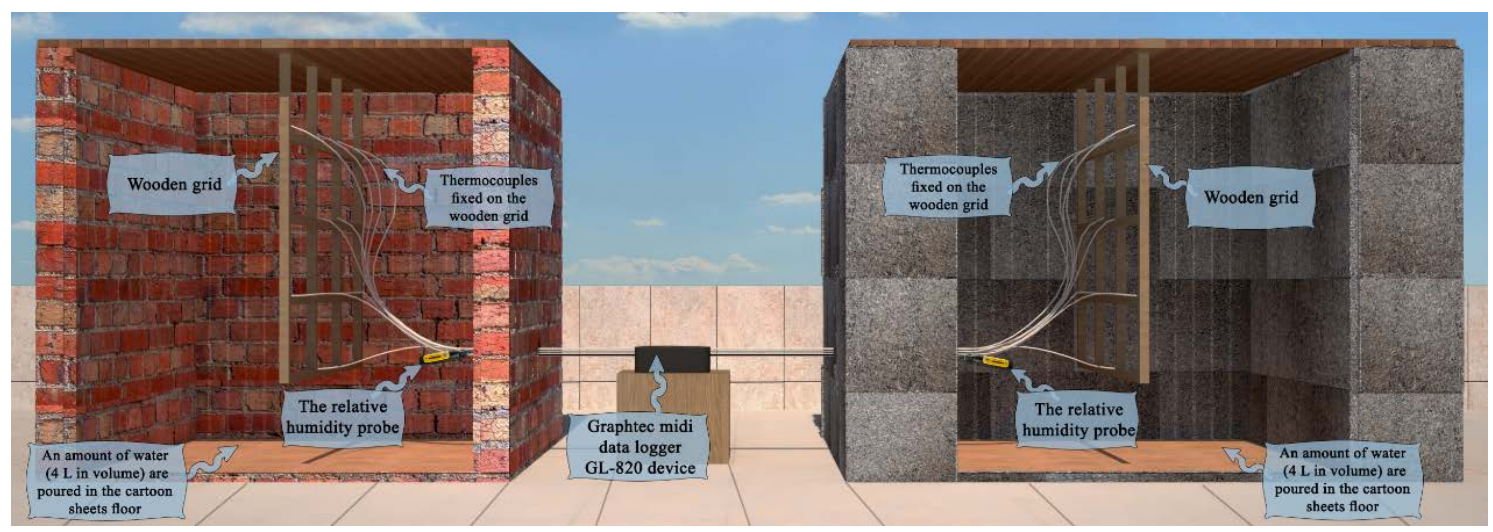

Figure 14. The measurements of relative humidity in the STB and WCHB models

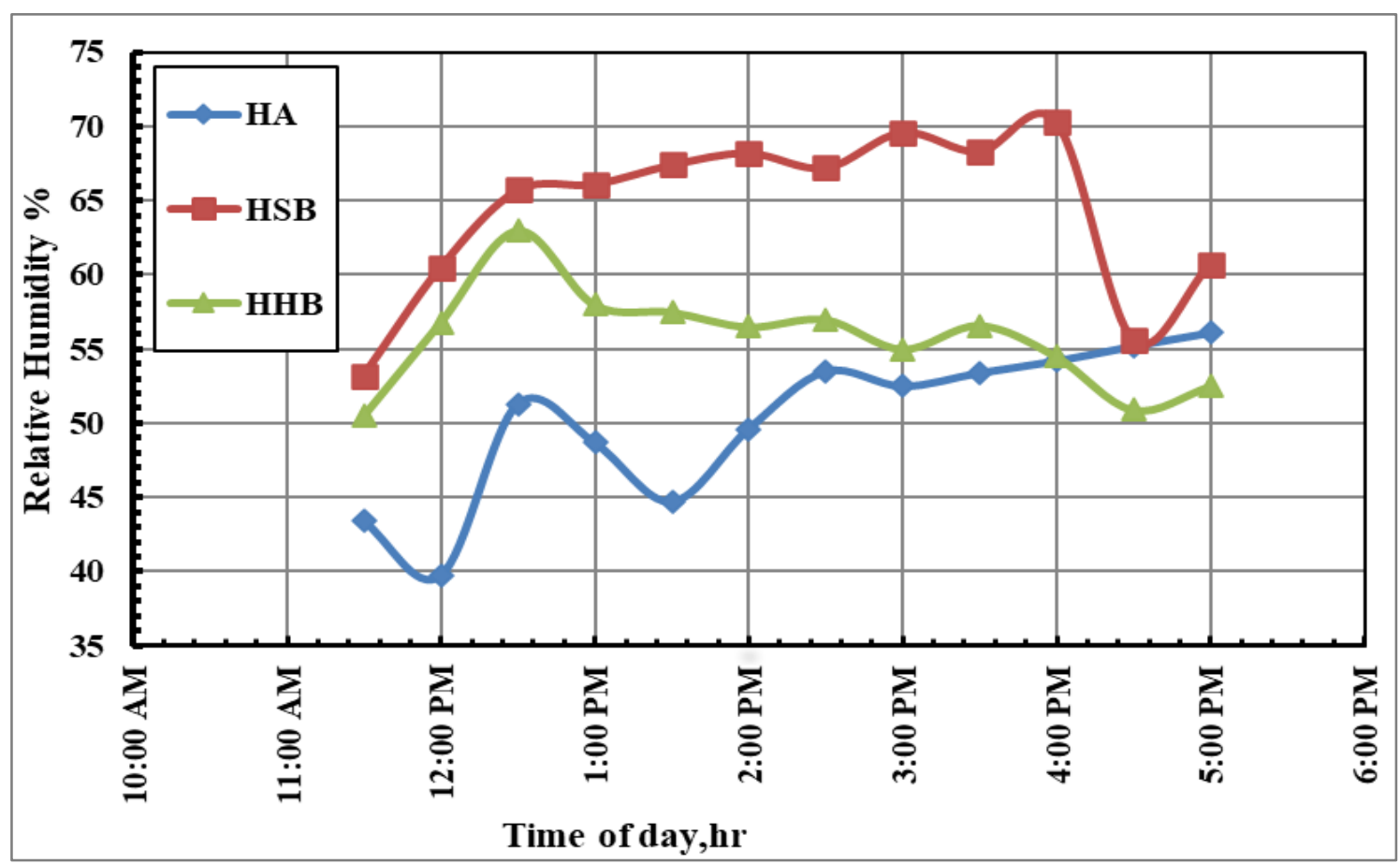

Figure 15. Humidity and time diagram in mid of September where HA: humidity of the air, HSB: humidity of Solid bricks model STB and HHB: humidity of hollow wood and cement bricks model WCHB 


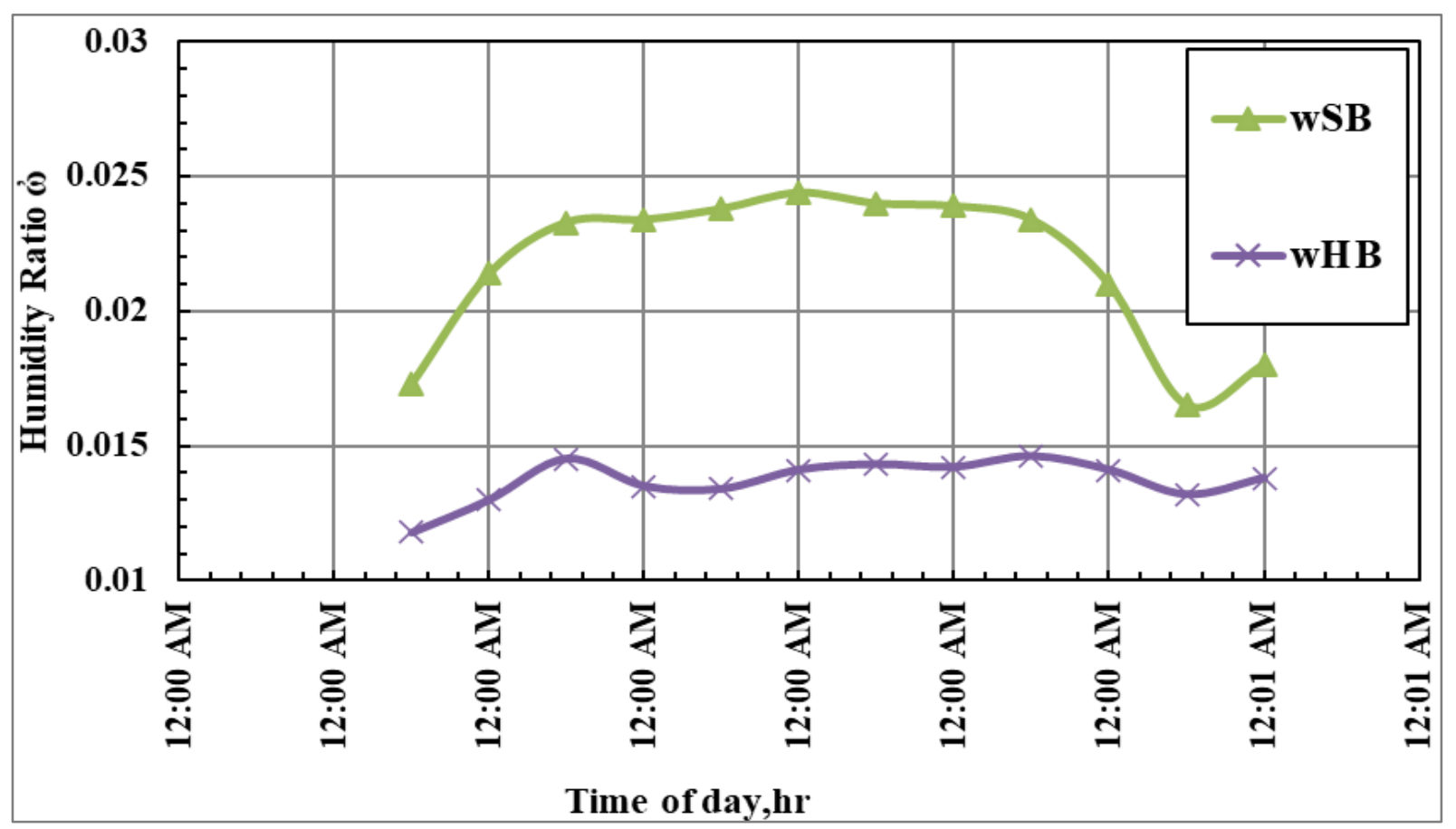

Figure 16. Humidity ratio $\omega$ per time diagram, where $\omega$ SB: humidity ratio of STB model and $\omega$ HB: humidity ratio of WCHB model, it is clear in the diagram that the humidity ratio $\omega$ in the WCHB model is much lower than that of the STB model

\section{Conclusions}

Smart BWs are one of the modern ideas that work on activating the performance of the building, adapting to environmental changes, and reducing the energy used for air-conditioning and refrigeration because it depends on natural ventilation more.

To measure and compare the efficiencies of the BW concept, a field experiment has been performed for five months in the summer of 2019 in June, July, August, September, and October in Port Said, Egypt, on the roof of the main building of the Faculty of Engineering. Two models were constructed and compared with each other. The first model was constructed with STBs, while the second was constructed with the proposed BW concept made of WCHB. Both models were made with the same inner dimensions $(100 \mathrm{~cm}$ width $\times 100 \mathrm{~cm}$ length $\times 100 \mathrm{~cm}$ height) and in the same orientation.

In our experiment, we measured the general elements (environmental parameters) in most of our internal spaces:

First, air temperature to compare the thermal performance of both models using the Graphtec midi data logger GL-820 and the results showed that the WCHB model was characterized by low thermal conductivity, which makes the temperature in it less than the STB model in the same conditions by about $3^{\circ} \mathrm{C}$ to $5^{\circ} \mathrm{C}$ because the vacuum in the middle of the WCHB model acts as an insulator that reduces the thermal gain.

Second, carbon dioxide $\left(\mathrm{CO}_{2}\right)$ concentration to compare the concentration of $\mathrm{CO}_{2}$ in the two models in the same conditions of temperature and pressure using the Aeroqual
S500 device, and the results showed that the measurements of the $\mathrm{CO}_{2}$ concentration in the WCHB model were lower than the STB model in the same conditions, where the maximum recorded $\mathrm{CO}_{2}$ concentrations in STB were $0.14 \%$, while the corresponding concentration in the WCHB model was $0.1 \%$. The concentration percentage wares till reaches the ambient concentration of $0.04 \%$ over $1 \mathrm{~h}$. The results of the measurements showed that the measurements of the $\mathrm{CO}_{2}$ concentration in the WCHB model were lower than those in the STB model by about $28.5 \%$ in the same conditions. This is because of the pores inside the wall, which can help to quickly spread the gas and thus reduce its concentration and help improve the quality of indoor air.

Third, indoor relative humidity: To compare the amount of humidity in the two models in the same conditions of temperature and pressure using the Graphtec midi data logger GL-820, and the results showed that the measurements of relative humidity were lower in the WCHB model than in the STB model by $\sim 41.66 \%$ in the same conditions. The air inside the WCHB model almost drew near the humidity of the external air. Then, the humidity of the air inside the WCHB model decreased compared to the external air, thus proving the permeability and the hygroscopic properties of the wall and that it is already a "BW."

From here, we report that that the WCHB model is better than the STB model in thermal performance, the concentration of $\mathrm{CO}_{2}$, and relative humidity in the same conditions of temperature and pressure. The WCHB model is ideal for dry, hot areas and hot, wet areas with high 
relative humidity such as coastal places.

Finally, this paper aims to improve air quality and achieve thermal comfort in internal spaces by using breathing walls, to provide sustainable preventive solutions in the future.

\section{REFERENCES}

[1] Alene, K. A., K. Wangdi, A. C. Clements, "Impact of the COVID-19 pandemic on tuberculosis control: an overview". Tropical Medicine and Infectious Disease, vol. 5, pp. 123, 2020. DOI: $10.3390 /$ tropicalmed5030123.

[2] Eltarabily, S., D. Elghezanwy, "Post-pandemic cities-the impact of COVID-19 on cities and urban design", Architecture Research, vol. 10, pp. 75-84, 2020, DOI: 10.5923/j.arch.20201003.02.

[3] Agarwal, N., C. S. Meena, B. P. Raj, L. Saini, A. Kumar, N. Gopalakrishnan, A. Kumar, N. B. Balam, T. Alam, and N. R. Kapoor, "Indoor air quality improvement in COVID-19 pandemic”, Sustainable Cities and Society, vol. 70, pp. 102942, 2021, DOI: 10.1016/j.scs.2021.102942.

[4] Megahed, N. A., E. M. Ghoneim, "Indoor Air Quality: Rethinking rules of building design strategies in post-pandemic architecture”, Environmental Research, vol. 193, pp. 110471, 2021, DOI: 10.1016/j.envres.2020.11047 1.

[5] Gabor, K., Tideren, "Breathing walls: A challenge for new sustainable building techniques in Hungary”, Building Industry Trends, pp. 123, 10281-10287, 2000.

[6] Swanson, G., O. Miller, and W. Federer, "Breathing Walls, Biological Approach to Healthy Building Envelope Design and Construction”, In. Book. 2008.

[7] Abo-Elazm, F., and S. Ali,” The concept of local smart architecture: An approach to appropriate local sustainable buildings”, International Journal of Cultural Heritage, vol. 2, pp. 1-12, 2017.

[8] Rickenbacker, H. J., W. O. Collinge, V. Hasik, A. Ciranni, I. Smith, P. Colao, A. L. Sharrard, and M. M. Bilec, "Development of a framework for indoor air quality assessments in energy conservation districts", Sustainable Cities and Society, vol. 52, pp. 101831, 2020, DOI: 10.1016/j.scs.2019.101831.

[9] Zhao, Y., H. Sun, and D. Tu, "Effect of mechanical ventilation and natural ventilation on indoor climates in Urumqi residential buildings”, Building and Environment, vol. 144, pp. 108-118, 2018,DOI:10.1016/j.buildenv.2018. 08.021.

[10] Liu, J., X. Dai, X. Li, S. Jia, J. Pei, Y. Sun, D. Lai, X. Shen, H. Sun, and H. Yin, "Indoor air quality and occupants' ventilation habits in China: seasonal measurement and long-term monitoring”, Building and Environment, vol. 142, pp. 119-129, 2018, DOI: 10.1016/j.buildenv.2018.06.002.

[11] Homod, R. Z., and K. S. M. Sahari, "Energy savings by smart utilization of mechanical and natural ventilation for hybrid residential building model in passive climate”, Energy and Buildings, vol. 60, pp. 310-329, 2013, DOI:

\subsection{6/j.enbuild.2012.10.034.}

[12] Schieweck, A., E. Uhde, T. Salthammer, L. C. Salthammer, L. Morawska, M. Mazaheri, and P. Kumar, "Smart homes and the control of indoor air quality", Renewable and Sustainable Energy Reviews, vol. 94, pp. 705-718, 2018.

[13] Abdulaali, H. S., M. M. Hanafiah, I. M. Usman, N. U. M. Nizam, and M. J. Abdulhasan, "A review on green hotel rating tools", indoor environmental quality (IEQ) and human comfort, vol. 29, pp. 128-157, 2020.

[14] Ahmed, T., P. Kumar, and L. Mottet, "Natural ventilation in warm climates: The challenges of thermal comfort, heatwave resilience and indoor air quality”, Renewable and Sustainable Energy Reviews, vol. 138, pp. 110669, 2021, DOI: 10.1016/j.rser.2020.110669.

[15] Osman, M., H. Ibrahim, F. Yousef, A. A. Elnasr, Y. Saeed, and A. A. Hameed, "A study on microbiological contamination on air quality in hospitals in Egypt”, Indoor and Built Environment, vol. 27, pp. 953-968, 2018.

[16] Wagdi, D., "Effect of building materials on indoor air quality in residential buildings in Egypt: A preoccupancy assessment”. 2015.

[17] Sundell, J., "Guidelines for Nordic building regulations regarding indoor air quality”, Environment International, vol. 8, pp. 17-20, 1982.

[18] Awbi, H. B., "Ventilation of buildings”, Routledge, 2002.

[19] Alongi, A., A. Angelotti, and L. Mazzarella, "Experimental validation of a steady periodic analytical model for Breathing Walls”, Building and Environment, vol. 168, pp. 106509, 2020, DOI: 10.1016/j.buildenv.2019.106509.

[20] Alongi, A., A. Angelotti, and L. Mazzarella, “Analytical modelling of Breathing Walls: experimental verification by means of the Dual Air Vented Thermal Box lab facility”, Energy Procedia, vol. 140, pp. 36-47, 2017.

[21] Alongi, A., A. Angelotti, and L. Mazzarella, "Experimental investigation of the steady state behaviour of Breathing Walls by means of a novel laboratory apparatus" Building and Environment, vol. 123, pp. 415-426, 2017, DOI: 10.1016/j.buildenv.2017.07.013.

[22] Craig, S., and J. Grinham, "Breathing walls: The design of porous materials for heat exchange and decentralized ventilation”, Energy and buildings, vol. 149, pp. 246-259, 2017.

[23] Elghawaby, M., "Breathing façades: a new concept to create dynamic thermal ambiances in buildings located in hot climates”, In: Ambiances in action/Ambiances en acte (s)-International Congress on Ambiances, Montreal 2012, International Ambiances Network, pp. 215-220, 2012.

[24] Shalaby, G., O. M Abo El Enein, A. M. Saif, and D. El Gheznawy, "Smart Breathing Wall for Integrated Ventilation: Heat Exchange and Indoor Air Quality Improvement”, Port-Said Engineering Research Journal, vol. 27, pp. 10-17, 2020. DOI: 10.21608/PSERJ.2020.2597 3.1038.

[25] Imbabi, M., "New developments in the science and art of breathing walls", Invited Speaker, Proceedings of WREC-VIII, Denver, 2004.

[26] May, N., "Breathability: The key to building performance”, 


$$
\text { p. (1-30), } 2005 .
$$

[27] Kosny, J., "Wooden concrete: High thermal efficiency using waste wood”, In. Oak Ridge National Lab., TN (United States), 1994.

[28] Latha, P., Y. Darshana, and V. Venugopal, "Role of building material in thermal comfort in tropical climates-A review”, Journal of Building Engineering, vol. 3, pp. 104-113, 2015.

[29] Elgheznawy, D., and S. Eltarabily, "The impact of sun sail-shading strategy on the thermal comfort in school courtyards”, Building and Environment, pp. 108046. 2021, DOI: 10.1016/j.buildenv.2021.108046.

[30] Van Belleghem, M., M. Steeman, A. Janssens, and M. De Paepe, "Heat, air, and moisture transport modelling in ventilated cavity walls", Journal of Building Physics, vol.
38, pp. 317-349, 2015.

[31] Bodrov, M., A. Smykov, M. Morozov, A. Shapoval, and V. Mironov, "Energy Efficiency of Radiant Heating Systems Based on Water-Based Radiant Profiles”, Civil Engineering and Architecture, vol. 9, pp. 1546-1557, 2021. DOI: 10.13189/cea.2021.090525.

[32] Kong, Y., and H. Davidson, "Dry sorbent injection of sodium sorbents for $\mathrm{SO} 2, \mathrm{HCl}$ and mercury mitigation”, In: North American Waste-to-Energy Conference, pp. 317-320, 2010.

[33] Koufi, L., S. Ginestet, and Z. Younsi, "Numerical prediction of surface radiation effect on thermal comfort and indoor air quality in a ventilated cavity heated from below" In: IOP Conference Series: Materials Science and Engineering. IOP Publishing, p 042043, 2019. 